\title{
RESPIRACIÓN VULNERABLE. REFLEXIONES ECOSÓFICAS SOBRE UN MUNDO IRRESPIRABLE
}

\author{
VULNERABLE BREATHING. ECOSOPHICAL REFLECTIONS \\ ON AN UNBREATHABLE WORLD
}

\author{
Mónica Cano Abadía \\ Universidad de Graz (Austria) \\ monica.cano-abadia@uni-graz.at
}

\section{ECOSOFÍA Y VULNERABILIDAD}

La ecosofía es un concepto de Felix Guattari ${ }^{1}$, un portmanteau de «ecología filosófica»: una filosofía de la ecología y el equilibrio. Guattari piensa la ecosofía en tres niveles interconectados de ecologías (la social, la mental y la medioambiental) que dan cuenta de la complejidad de las interrelaciones e intraacciones ${ }^{2}$ de lo humano, lo planetario y lo animal.

Este breve artículo propone llevar la perspectiva ecosófica a las consideraciones sobre la vulnerabilidad. En el seno del posthumanismo crítico y el neomaterialismo feminista hay ciertas reticencias a incorporar el concepto de vulnerabilidad pues parece remitir en ocasiones a un marco de comprensión negative (léase, hegeliano) que hace perder de vista la afirmación de la vida ${ }^{3}$. En un reciente texto, Miryam Hernández y yo hemos estado trabajando en definir una vulnerabilidad posthumana ${ }^{4}$ : una vulnerabilidad entendida, con Judith Butler ${ }^{5}$, como un aspecto constitutivo de la vida que no se puede ignorar y al que hay que atender precisamente para poder afirmar la vida. Una vulnerabilidad, además, que es postantropocéntrica pues el ser

1 Guattari, F. (1990). Las tres ecologías, Valencia, Pre-textos.

2 BARAD, K. (2007). Meeting the Universe Halfway: Quantum Physics and the Entanglement of Matter and Meaning. Durham, Duke University Press. Para ahondar en la definición de intra-acción, véase: Whitney Stark (2016). Intra-action. Disponible en https://newmaterialism.eu/almanac/i/intraaction.html (consultado el 11 de octubre de 2021).

${ }^{3}$ Braidotti, R. (2006). Affirmation versus Vulnerability. On Contemporary Ethical Debates. Canadian journal of continental philosophy 10(1), pp. 235-254.

${ }^{4}$ Henández Domínguez, M. y Cano Abadía, M. «Vulnerabilidad Posthumana» en M. Mandujano y M. Hernández Domínguez (coord.), Ética y politica: ensayos indisciplinados para repensar la filosofía, Granada, Comares, pp. 139-148.

5 Butler, J. (2006). Vida Precaria. El poder del duelo y la violencia, Buenos Aires, Paidós.

DOI: https://doi.org/10.25145/j.laguna.2021.49.07

Revista LagunA, 49; diciembre 2021, pp. 103-108; ISSN: e-2530-8351 
humano es vulnerable, las relaciones humanas son vulnerables, el planeta es vulnerable, los animales son vulnerables, las infraestructuras son vulnerables.

Se propone en lo que sigue una serie de reflexiones sobre la vulnerabilidad y la respirabilidad atendiendo a las vulnerabilidades sociales, mentales y medioambientales; vulnerabilidades que, por supuesto, desde una perspectiva ecosófica, intraactúan.

\section{RESPIRACIÓN Y LA VULNERABILIDAD SOCIOCORPORAL}

Desde los nuevos materialismos ${ }^{6}$, es pertinente entender el respirar en relación con su comonalidad corpormaterial. El respirar nos hace tener vida. Los seres humanos vivos siempre respiramos, no hay vida humana sin respirar. Nuestro cuerpo necesita respirar para mantenerse vivo. También es un acto que difumina las fronteras entre el adentro y el afuera del cuerpo: es un constante metabolismo del cuerpo en movimiento a través de los pulmones; fluir de oxígeno por las venas, órganos y células. Habla de nuestra porosidad como cuerpos. El aire entra pero no entra solo: partículas de otros cuerpos, microbios, virus, polen entran en nuestro cuerpo. Algunos de esos elementos pasan a formar parte de nuestra corporalidad, o modifican nuestro cuerpo para siempre. Expulsamos aire: expulsamos microbios, virus, que entran en otros cuerpos, que se colocan en superficies que otras personas tocan ${ }^{7}$. Ese mundo en común es ahora un peligro, y hace que respirar sea riesgoso. Y esto es así porque somos vulnerables. Somos seres expuestos al Otro, y esa exposición es imprevisible. Esto es así porque no somos seres invulnerables, la invulnerabilidad es una fantasía del sujeto liberal que ya está obsoleta ${ }^{8}$ : es falsa y tiene efectos perniciosos. Pensar en un sujeto vulnerable es mucho más adecuado y, además, estimulante para nuestras reflexiones éticas y políticas.

Respirar, pues, aunque no nos demos cuenta casi de que lo hacemos, no es un acto ni simple ni homogéneo: hay un reparto diferencial de las posibilidades de respirar; se hace necesario, pues, un análisis interseccional, encarnado y situado (ecosófico, además) de la política del respirar. Hay diferentes capacidades respiratorias según las posibilidades de respirar con un pulmón colapsado, con cáncer, con pulmones de diferentes tamaños, con ansiedad, con covid-19. Es algo que puede mejorar o empeorar en ciertas condiciones materiales (internas o externas al cuerpo propio); es algo que se puede entrenar; es una capacidad que se puede perder. Desde una perspectiva postantropocéntrica, además, el respirar es algo que no pertenece a

${ }^{6}$ Véanse: Alaimo, S. y Hekman, S. (eds.) (2013). New Materialisms., Indiana University Press, 2008; Van der Tuin, I. y Dolphijn, R. New Materialism: Interviews and Cartographies. Open Humanities Press.

7 Butler, J. (2020). «Rastros humanos en las superficies del mundo». Disponible en https://contactos.tome.press/rastros-humanos-en-las-superficies-del-mundo/?lang=es (consultado el 13 de octubre de 2021).

${ }^{8}$ Butler, J. (2021). La fuerza de la no violencia. La ética en lo politico, Barcelona, Paidós. 
la singularidad humana. Muchos seres vivos (plantas, animales terrestres o acuáticos, microorganismos) respiran, de maneras diferentes. Nuestras células también respiran.

Magdalena Gorská ${ }^{9}$ habla de la respirabilidad y la política de luchar por vidas respirables; la lucha por seguir respirando. La invisibilidad del respirar hace que parezca un asunto menor, pero sostiene nuestras vidas. El respirar importa y se materializa. El respirar es posible en ciertas condiciones físicas (propias y ajenas), psicológicas, medioambientales, socioeconómicas; forma parte de lo político. Sobre todo, los asuntos respiratorios son relevantes en las actuales normas sociales y relaciones de poder sofocantes. La precaridad de las vidas irrespirables. ¿Qué cuerpos pueden respirar? ¿Qué cuerpos se ven abocados a asfixiarse por falta de infraestructuras y condiciones de vida decentes?

\section{VULNERABILIDAD MEDIOAMBIENTAL Y LA RESPIRABILIDAD EN EL ANTROPOCENO ${ }^{10}$}

Tres textos son de ayuda para reflexionar sobre las condiciones de respirabilidad en el Antropoceno ${ }^{11}$. Tobias Menely ${ }^{12}$ conceptualiza el término «el aire del Antropoceno", que puede caracterizarse en parte por el crecimiento de los niveles de gases de efecto invernadero a una velocidad fuera de sincronía con otros sistemas terrestres. Pero el aire del Antropoceno es también las bolsas y los intercambios de materia atmosférica en los espacios locales y cotidianos, que también se configuran micropolíticamente. El aire es una cuestión histórica, escribe Menely, pesado y espeso con una temporalidad decisiva. La caracterización que hace Menely del aire del Antropoceno se inspira en lecturas transdisciplinares sobre el aire y la atmósfera: novelistas que demuestran que el aire puede expresar condiciones sociales y políticas; médicos y expertos en salud pública que documentan relaciones entre el aire y

9 Gorská, M. (2016). Breathing Matters: Feminist Intersectional Politics of Vulnerability. Universidad de Linköping. Breathing Matters es un interesante título, al estilo de Bodies that Matter (traducido Cuerpos que importan) de Butler. Teniendo en cuenta ese doble significado del verbo matter en inglés: el respirar se materializa, el respirar importa; se puede añadir un tercer significado: asuntos respiratorios.

10 Para consultar textos fundacionales del concepto de "Antropoceno", véanse Crutzen, Paul, J. (2002). Geology of mankind: the Anthropocene. Nature, 415 (23); STEFFEN, W. et al. (2015). "The trajectory of the Anthropocene: the Great Acceleration». The Anthropocene Review, 2 (1): 81-98. Zalasiewicz, J. et al. (2011). The Anthropocene: a new epoch of geological time? Philosophical Transactions of the Royal Society, 369: 835-841.

${ }^{11}$ En este texto, se traza una simple reflexión utilizando tres textos. Para otras reflexiones previas sobre el Antropoceno y la vulnerabilidad, véanse: Cano Abadía, M. (2017) Cartografías ecosóficas y situadas. Hacia una justicia zoecentrada y feminista. Ecología Política: 42-49; Cano AвAdía, M. (2017). Algunos animales somos más iguales que otros. Hacia una zoedanía materialista. GénEros 24 (21): 75-94.

12 Menely, T. (2014). «Anthropocene Air», Minnesota Review 83: pp. 93-101. 
la enfermedad; activistas medioambientales que utilizan el derecho al aire limpio como un punto de apoyo fundamental en demandas de justicia.

En segundo lugar, Gorská desarrolla lo que llama una política medioambiental del aire contaminado como parte de su preocupación interseccional por la justicia. En su libro, les hace entrevistas a ciertas personas: Anna, una trabajadora sexual por teléfono que utiliza el respirar como práctica; o Marek, un exminero de una mina de carbón checoslovaca. Gorská analiza las diferencias espaciotemporales y corpomateriales de los sujetos que entrevista. En el caso de Marek, se vio expuesto durante años a aire polvoriento que le hacía toser y escupir flema negra todos los días. Su experiencia fue tremendamente dura y, aunque no fue diagnosticado oficialmente con pneumoconiosis, sufre de lo que llama «pulmones polvorientos». Fue uno de los privilegiados porque tenía estudios y pudo cambiar rápido de posición: sólo estuvo dos años en el lugar más polvoriento de la mina. Otros de sus compañeros se quedaron allí para siempre y perdieron la vida a causa de la enfermedad de los pulmones polvorientos. El respirar de Marek es una cuestión naturocultural que se inserta en ciertas relaciones de poder. La desigual exposición al aire contaminado que existe entre grupos privilegiados y no privilegiados es un factor a tener en cuenta cuando analizamos las enfermedades contemporáneas (la covid-19 es un buen ejemplo).

En Bodily Natures ${ }^{13}$, Stacy Alaimo introduce en los debates ecofeministas contemporáneos el concepto del "pulmón proletario». Analiza este concepto a través de archivos históricos de la resistencia de trabajadores en relación con el desarrollo de prácticas del cuidado de la salud. Alaimo toma este concepto de otros autores (Lewontin y Levins $)^{14}$ que trabajan sobre la relación ente la clase, la raza y la corporalidad y lo desarrolla más allá para articular la transcorporeidad de la corpomaterialidad y para desafiar los límites de la conceptualización de los cuerpos humanos y no humanos. El pulmón proletario se ve expuesto al amianto, al carbón, al polvo, a la radiación, al humo, a productos tóxicos. El pulmón está en el interior de quien trabaja, pero también se ve sometido a escrutinio por la medicina, la ley, la higiene industrial, los seguros médicos, los sindicatos, las académicas que se ocupan de estos asuntos, etc. El pulmón proletario ilustra que el cuerpo humano no está nunca cerrado de manera rígida sino que es vulnerable a los flujos del entorno (entornos industriales y sus fuerzas sociales y económicas). Hay una intraacción entre la corpomaterialidad, las normas culturales y las relaciones de poder. El pulmón proletario demuestra cómo la opresión de clase (y de raza) penetra en el cuerpo: lo biológico y lo social no se pueden considerar como esferas separadas.

13 Alaimo, S. (2010). Bodily Natures. Science, Environment and the Material Self, Indiana University Press.

${ }_{14}$ Lewontin, R. y Levins, R. (2007). «Biology under the Influence: Dialectical Essays on Ecology, Agriculture, and Health» Monthly Review Press. 


\section{VULNERABILIDAD MENTAL Y LAS RESPIRACIONES ANSIOSAS}

Hay una fuerte asociación entre la ansiedad y los síntomas respiratorios, incluyendo la falta de aliento, la hiperventilación y la respiración poco profunda. La respiración superficial, o respiración torácica, es la aspiración de una cantidad mínima de aire hacia los pulmones, generalmente mediante la aspiración de aire hacia el área del pecho usando los músculos intercostales en lugar de a través de los pulmones por medio del diafragma. Ocurre cuando se tiene asma, o ansiedad, o covid-19.

La ecoansiedad es un fenómeno reciente que tiene que ver con nuestra posición como seres vulnerable en el Antropoceno. La Asociación Americana de Psicología definió por primera vez la ecoansiedad en 2017 como «un miedo crónico a la fatalidad medioambiental $\aleph^{15}$. La ecoansiedad se refiere al miedo al daño medioambiental o al desastre ecológico. Esta sensación de ansiedad se basa en gran medida en el estado actual y en las previsiones futuras del medio ambiente y del cambio climático. Como seres vulnerables e interconectados, percibimos el peligro inminente que amenaza a muchas personas, animales, ecosistemas. La situación medioambiental planetaria actual nos somete a un tipo de violencia lenta ${ }^{16}$ que hace que nuestra salud mental sufra de manera profunda.

En ocasiones, la ansiedad es crónica: una vida entera de respiración superficial, de hiperventilaciones y de pánico. Es el caso de Katie Strom ${ }^{17}$, quien explica que en el verano de 2018 experimentó una implosión mente-cuerpo que la dejó fuera de servicio durante aproximadamente doce meses. Strom es una académica posthumana y neomaterialista, profesora de profesores en la universidad, una profesional capaz de llevar teoría compleja a lo vivencial y lo práctico. No obstante, con su experiencia con la ansiedad, se dio cuenta de que eso no era así. La ansiedad le enseńó que seguía atascada en un modelo racional-humanista del cuerpo que le animaba a ser dueña de sí misma, a controlar su respiración, sus pensamientos desbocados, su arritmia y todos los síntomas de la ansiedad que vivía en su cuerpo. Su respuesta encarnada a la ansiedad fue la del sujeto liberal autónomo, libre, autoconsciente, y dueño de sí mismo.

Para ella, esto supuso una vuelta al Spinoza básico y su enseñanza de que hay pensamientos en la mente y sentimientos en el cuerpo (uno necesariamente viene antes que el otro, y están conectados, enredados). A medida que los pensamientos se desbocan, los síntomas del cuerpo se intensifican. Para aplacar el cuerpo, adoptamos conductas de evitación, como ver la televisión todo el día. Estos com-

15 Clayton, S., Manning, C., Krygsman, K. y Speiser, M. (2017). Mental Health and Our Changing Climate: Impacts, Implications, and Guidance. Washington, D.C.: American Psychological Association, and ecoAmerica.

${ }^{16}$ Nixon, R. (2013). Slow Violence and the Environmentalism of the Poor. Harvard University Press.

17 Strom, K. (2020). «Learning from a 'Lost Year': An Autotheoretical Journey through Anxiety and Panic». Capacious: Journal for Emerging Affect Inquiry 2 (3). 
portamientos de evasión producen más pensamientos negativos que a su vez están intraactuando con sensaciones corporales negativas. Hay un ciclo mente-cuerpo. Katie Strom descubrió que centrarse en el cuerpo era la solución a su ansiedad (a través del deporte y medicación).

\section{CONCLUSIONES}

El respirar es una cuestión materiocorporal en intraacción con relaciones de poder. Como seres vulnerables e interconectados, percibimos los efectos de la irrespirabilidad del mundo tanto física como mentalmente.

En un texto reciente, Achille Mbembe ${ }^{18}$ considera que debemos responder aquí y ahora por nuestra vida en la Tierra con los otros, entiendo por «los otros» una multitud de seres vivos y no vivos, incluyendo los virus. Tal es el mandato que este período patógeno exige a la humanidad. Tenemos un destino compartido y debemos hacernos responsables por mejorar las condiciones de respirabilidad en este planeta.

Como cierre, unas elocuentes palabras de Mbembe con respecto al derecho universal a la respiración que encapsulan algunos aspectos (los referents a los animals humanos) que este breve texto ha querido transmitir:

Si tiene que haber guerra, no puede ser tanto contra un virus específico como contra todo lo que condena a la mayoría de la humanidad a un cese prematuro de la respiración, todo lo que ataca fundamentalmente a las vías respiratorias, todo lo que, en el largo reinado del capitalismo, ha constreñido a segmentos enteros de la población mundial, a razas enteras, a una respiración difícil y jadeante y a una vida de opresión. Superar esta constricción significaría que concebimos la respiración más allá de su aspecto puramente biológico, y en cambio como aquello que tenemos en común, aquello que, por definición, escapa a todo cálculo. Con lo que quiero decir, el derecho universal a la respiración.

RECIBIDO: noviembre 2021; ACEPTADO: noviembre 2021

${ }_{18}$ Mвемbe, A. «El derecho universal a respirar». Reflexiones sobre el covid en abril de 2020 recuperado de https://terremoto.mx/revista/the-universal-right-to-breathe/. 